\title{
Efficacy of percutaneous transluminal angioplasty on dysfunctional fistulae because of inflow stenosis
}

\author{
Fernando Caeiro, Dulce Carvalho, João Cruz, João Ribeiro Santos, Fernando Nolasco \\ Department of Nephrology, Hospital Curry Cabral - Portugal
}

\begin{abstract}
Purpose: Autogenous fistulas are the preferential vascular access for hemodialysis. The aim of this retrospective study was to determine the efficacy of angioplasty for dysfunctional fistulas because of inflow dysfunction.

Methods: We reviewed all the angiographic procedures performed on our institution between April 2007 and April 2009. Procedures performed in dysfunctional fistulas because of inflow stenoses were analyzed. Fistulas with stenoses out of these areas were excluded. The following data were collected: patient age and sex, fistula age at the time of intervention, location of fistula, number and location of stenosis, angiography referral criteria, clinical findings (presence or absence of thrills, bruits and pulsatility) and date of reintervention or failure.

Results: During the study period 215 fistulas were submitted to angiography of which, seventy-one presented inflow stenosis $(33 \%)$. Mean follow-up was $21.72 \pm 9.26$ months, and average age was 7.03 months. Two groups were considered: 31 fistulas comprising $\leq \mathbf{6}$ months old, and 40 fistulas $>\mathbf{6}$ months old. Primary patency rates \pm SE for older fistulas at $6,12,18$ and 24 months, respectively, was $91.3 \% \pm 0.04 \%, 80.7 \% \pm 0.07 \%, 53.8 \% \pm 0.10 \%$ and $34.2 \pm 0.1 \%$. versus $91.7 \pm 0.08 \%$, $57.1 \pm 0.14 \%, 23 \pm 0.14 \%, 11.4 \% \pm 0.1 \%$ for younger fistulas $(P=0.04)$. Fistulas $\leq 6$ months old and multiple stenosis were associated with a poorer primary patency rate $(P=0.005)$.

Conclusions: Inflow stenosis is frequently associated with fistula dysfunction. In this study we only analyzed AVF with inflow stenosis and we have shown that angioplasty can have great patency results, particularly for single lesions in matured fistulas.
\end{abstract}

Key words: Angioplasty, Inflow stenosis, Vascular access

Accepted: October 10, 2012

\section{INTRODUCTION}

Regardless of the development in nephrologic care, chronic kidney disease patients still have a high morbidity and mortality, mainly because of vascular related dysfunction, as demonstrated by the DOPPS study (1). Pisoni et al have revealed that the increased prevalence of central venous catheters and grafts was associated with considerably higher mortality and hospitalization risks (2). The European Best Practice Guidelines (EBPG) recommend the placement of arterio-venous fistulas over grafts (3), nonetheless, $28 \%$ to $53 \%$ of fistulas will not mature upon creation to support dialysis therapy and $10 \%$ to $80 \%$ will suffer from dysfunction in the long-term (4-6).

Percutaneous transluminal angioplasty (PTA) has proven to be valuable for management of dysfunctional fistula (7-11), and in 1997, American KDOQI guidelines acknowledged for the first time the role of interventional angioplasty for treatment of vascular access dysfunction (6). In the last few years, several studies have demonstrated that this technique is efficient and safe, enabling preservation of veins, avoiding the need for a new access and eventually the need for catheter while the new access matures (7-10).
The aim of this study was to assess the success and complication rates for PTA in the treatment of fistula malfunction because of inflow stenosis regardless of the degree of maturation.

\section{MATERIALS AND METHODS}

An inflow stenosis was defined as stenosis within the following areas: the feeding artery, the artery-vein anastomosis comprising $1 \mathrm{~cm}$ of vessel length on both sides of the anastomosis and the juxta-anastomotic region (the first $2 \mathrm{~cm}$ downstream from the anastomosis) (12) and drainage vein which involved the puncture area. All fistulas with stenoses outside this area were excluded.

The referral criteria analyzed in dysfunctional fistula were one of the following: 1) insufficient development after one month upon creation, 2) difficulties in cannulation, 3) inability to deliver $300 \mathrm{~mL} / \mathrm{min}$ dialysis flow, 4) prolonged hemostasis and 5) inadequate $\mathrm{Kt} / \mathrm{V}$. Vascular stenosis was defined as significant if it caused $a \geq 50 \%$ reduction in luminal diameter judged by comparison with the adjacent vessel or graft. Stenoses were considered sim- 
ple, if unique, or multiple, if more than one. Clinical assessment of the fistula included the detection of abnormal findings of weak or absence of thrill, pulsatility, changes in bruits, and direct palpation of stenosis. Clinical variables included patient age and sex, fistula age at the time of procedure, location of fistula, number and location of stenosis, type and number of interventions performed in each fistula, date of failure or reintervention.

All interventions were performed in patients on regular hemodialysis sessions and as outpatient procedures by two nephrologists trained in vascular intervention for at least six years. Infection was the only absolute contraindication for the procedure. Surgical revision on the previous 10 days and iodine allergic reaction were considered relative contraindication.

Angiography was performed by a venous retrograde approach, using direct puncture of the vascular access using an $18 \mathrm{G}$ needle and placement of a $7 \mathrm{~F}$ or $8 \mathrm{~F}$ dilator introducer sheath since those were the only ones available in our center. Local analgesia was provided by lidocaine administration at the puncture site and at the site of stenosis. If a stenosis was present, a wire was passed and the appropriately high-pressure balloon catheter was then advanced to the stenotic area. Stenoses were treated using a standard angioplasty technique with high pressure balloons ('Blue-Max', Medi-Tech, Natick, Ma, or 'Centurion', Bard, Covington, GA, USA). The balloon was then inflated up to the maximal recommended pressure and/or to abolish the waist of the stenosis on the balloon for up to two minutes. The size of the balloons was dependent of the size of the adjacent vessels. No anticoagulant or other intravenous medication was used. The final result was assessed clinically and angiographically, respectively; reappearance of a countinuous thrill over the access and stenosis disappearance. Blood flow was also assessed at the end of the procedure, analyzing the velocity of blood upon administration of intravenous contrast. In cases of dilation-induced rupture of the vein, the dilation balloon was first reinflated locally at low pressure $(6-8 \mathrm{~atm})$ for periods of 10 minutes, up to three times. If the rupture persisted, stent placement would have been considered.

\section{Definitions and end points}

Primary and secondary patencies after intervention were defined according to the Society of Interventional Radiology (SIR) (13-14). Primary patency was defined as patency during the interval between primary intervention and fistula thrombosis or repeated radiologic intervention. Secondary patency was defined as patency during the interval between primary intervention and the time when the fistula had surgical intervention or is abandoned. Cumulative patency was considered as the total time the access remains patent regardless of interventions.

After angiographic intervention, two definitions were used, clinical and anatomic success. Clinical success was considered positive if the fistula provided adequate dialysis for at least one session, at $300 \mathrm{~mL} / \mathrm{min}$ flow rate without recirculation. This was achieved by consultation of the dialysis charts or questioning the medical team. Anatomic success was defined if the stenosis disappeared.

\section{Follow-up}

All the information for each patient was obtained from medical records maintained by the dialysis unit. Complications were categorized as major or minor as published guidelines of the SIR (14). Complications associated with impaired clinical consequences, death, need for an additional intervention or inpatient hospitalization were considered major.

\section{Statistical analysis}

Primary and secondary patency rates were estimated using the Kaplan-Meier life-table method, and tested using the log rank test. All fistulas surviving up to the end of the study were considered and data censored if the patients were lost to follow-up, dead with a patent fistula, transferred to another dialysis center or submitted to kidney transplant and, subsequently, without any information available on the status of the fistula.

The Student $t$ test or Wilcoxon rank sum test were used for univariate analysis of continuous variables; categoric variables were assessed using the $\chi^{2}$ or Fisher exact test, as appropriate. A P value of 0.05 was used to determine statistical significance. Cox proportional hazards regression model was performed for primary patency using the following factors: patient age and sex, type of fistula, side of fistula, age of the fistula before first intervention (less than or equal to six months or more than six months), number of venous stenosis dilated ( $n=1$ vs. $n>1$ ) and the location of the stenosis (with arterial versus without arterial involvement).

\section{RESULTS}

From April 2007 to April 2009, 215 patients with dysfunctional fistulas were analyzed. One hundred and sixteen patients presented vascular stenoses in the outflow area. In 28 patients, dysfunctional fistulas were because of the presence of several collateral vessels. Both these groups were excluded. Seventy-one patients presented an inflow stenosis (33\%) (Fig. 1).

Table I shows demographic data for this group of patients. Patients were followed for $21.72 \pm 9.26$ months, median 19.98 months (minimum seven months, maximum 31 months), mean age 64 years old, $57.7 \%$ men. At the time of intervention, fistula age had a median of 7.03 months. Thirty-one fistulas $(43.7 \%$ ) were less than six months, with a mean age of $3.77 \pm 1.11$, median 3.58 (1.9 to 5.6 months) and 40 fistulas (56.3\%) were older than 
six months, with a mean age of 21.62 months, median 11.50 (6.2 to 161 months). Most fistulas were brachiocephalic $(46.5 \%)$ and $64.7 \%$ were located on the left side. In the group of fistulae $\leq 6$ months, $54.8 \%$ were radiocephalic and $35.5 \%$ were brachiocephalic and in fistulae $>6$ months, $39 \%$ were radiocephalic and $52.8 \%$ brachiocephalic. The most frequent criteria of fistula dysfunction was insufficient development $(22.5 \%)$ and inability to deliver $300 \mathrm{~mL} / \mathrm{min}(42.3 \%)$ of blood flow. All the fistulas were very pulsatile and a weak or absent thrill was noted. In 15/71 cases, no procedure was performed, and the patients were referred to surgery (Fig. 1). In eight of these fistulas, two radiocephalic and six brachiocephalic, there was complete occlusion of the venous outflow approximately 4-6 cms after anastomosis. These fistulas had a mean age of eight months, median four months; two of them were 17 and 25 months old. A wire and a catheter were tried through the stenosis, but unsuccessfully. In six fistulas, the stenosis was critical, being located at the anastomosis $(>90 \%)$ and associated with a reduction in the caliber of the radial artery over its entire extension up to the elbow. The last patient presented a stenotic lesion in the venous outflow associated with an important aneurism lesion in the juxta-anastomotic area.

TABLE I - DEMOGRAPHIC DATA

\begin{tabular}{lc}
\hline Variable & Patients (n=71) \\
\hline Age of patient (y) & $64 \pm 14$ \\
Sex & \\
$\quad$ Male & $41(57.7 \%)$ \\
$\quad$ Female & $30(42.3 \%)$ \\
Type of Fistula & \\
Radiocephalic & $32(45.1 \%)$ \\
Brachiocephalic & $33(46.5 \%)$ \\
Transposed brachiobasilic & $6(8.5 \%)$ \\
Side of Fistula & \\
Left & \\
Right & $48(67.6 \%)$ \\
Age of Fistula at first intervention (mean) & $23(32.4 \%)$ \\
Number of Fistula & 14, median 7.03 \\
$<6$ months old versus $>6$ months old & \\
Criteria of dysfunction & 31 Fistula versus 40 fistula \\
Insufficient development & \\
Difficulties in cannulation & $16(22.5 \%)$ \\
Inability to deliver 300 mL/min & $12(16.9 \%)$ \\
Prolonged hemostasis & $30(42.3 \%)$ \\
Inadequate Kt/V & $6(8.5 \%)$ \\
\hline
\end{tabular}

$y$, years

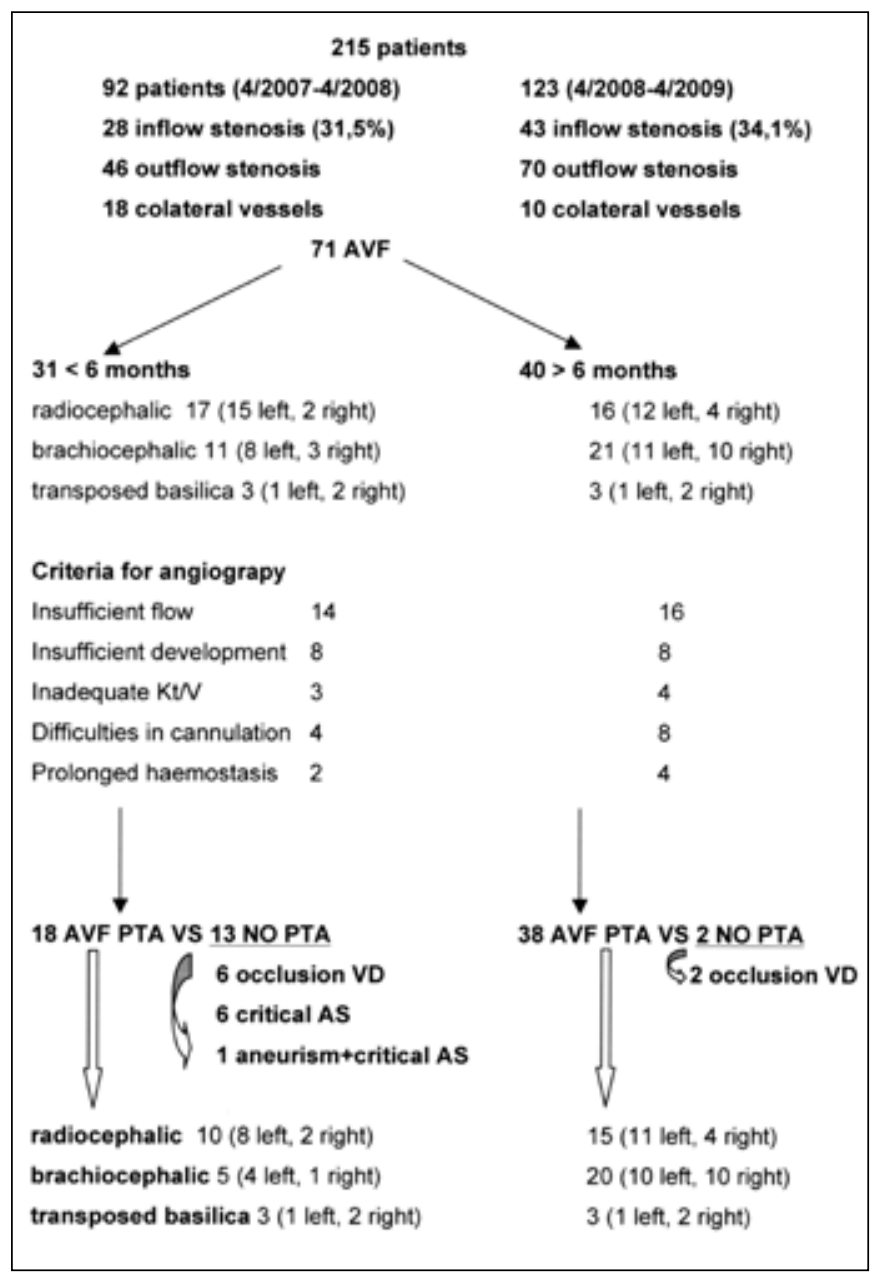

Fig 1 - Scheme representing all the fistulas (AVF) submitted to angiography $(A S=$ arterial stenosis; $V D=$ vein drainage, $P T A=$ percutaneous angioplasty).

Angioplasty was performed in 56 cases. Thirty-eight fistula out of 41 , older than six months, underwent angiographic procedure compared to only $18 / 31$ fistula less than six months old ( $P=0.00025$, Fisher's exact test ).

Single stenoses were the predominant lesion in $59.2 \%$ of cases (Tab. II). These lesions were predominantly located at the puncture and juxta-anastomosis areas. Multiple lesions also predominantly affected the juxta-anastomosis and puncture areas. In 10 cases (14.1\%), the artery was affected, and angioplasty was successful in 6/10 (60\%) cases. One of these patients had multiple stenotic lesions along the radial artery up to the elbow and successfully underwent PTA.

Fistulas younger than six months presented predominantly single stenosis $(74.2 \%)$ and fistulas older than six months old mainly showed multiple lesions in $52.5 \%$ ( $\mathrm{P}=0.08$, Fisher's exact test).

Angioplasty had an anatomic success of $100 \%$, achieved in 56/56 patients and a clinical success in $98.2 \%$ attained in $55 / 56$ patients. All the successfully treated fistulas recovered a 


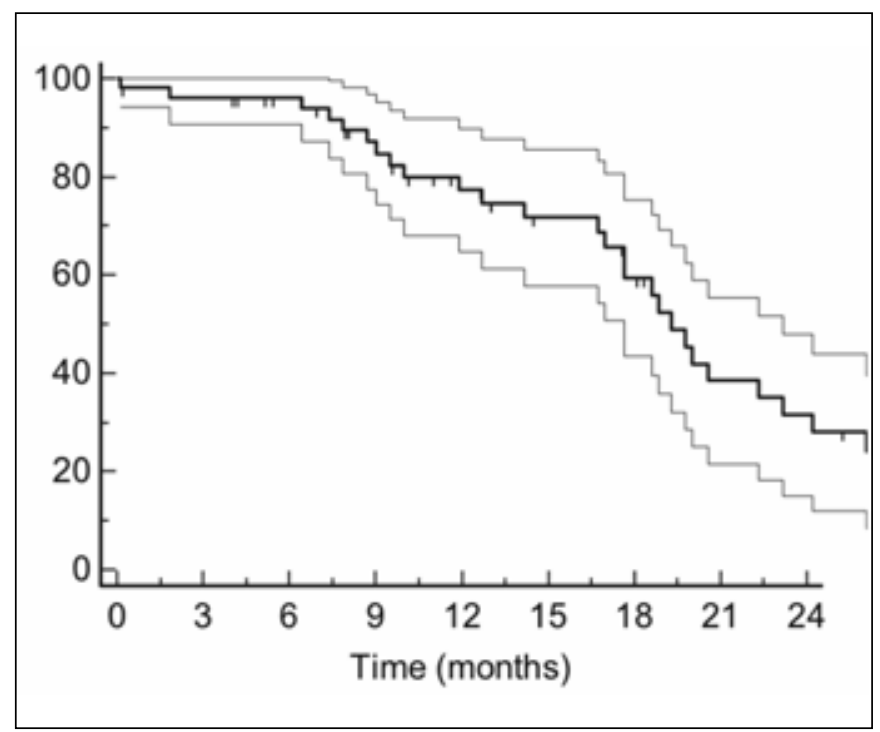

Fig. 2 - Kaplan Meier curve of estimated primary patency after first angioplasty in all fistulas. Crosses indicated censored observations 95\% confidence intervals are represented by the less dark line.

strong thrill and the pulsatility disappeared. Intention to treat analysis revealed a clinical success in $77.5 \%$.

During the follow-up period 11 patients died with a functioning access and one patient underwent renal transplant, still having a functioning fistula at the end of the study. Nine patients suffered fistula thrombosis, and seven patients required a total of 10 repeated successful endovascular procedures. The total fistula event rate was 0.18 events/accessyear. The fistula loss rate was 0.08/access-year.

Figure 2 shows the Kaplan-Meier curve of estimated primary patency after first angioplasty in all fistulas. Estimated median survival was 19.3 months and mean primary patency rate \pm standard error(SE) at $6,12,18$ and 24 months was $93.9 \% \pm 3.44 \%, 77.2 \pm 6.4 \%, 52.4 \% \pm 8.5 \%$ and $28 \pm 8.1 \%$, respectively.

Table III shows the survival rates for radiocephalic and brachiocephalic fistulas. No statistically significant difference was found between the survival rates $(\mathrm{P}=0.6$, logrank test). No analysis was performed for transposed basilica, because of a reduced number of this type of fistula.

Kaplan-Meier curve of estimated primary patency after first angioplasty for fistulas older than six months revealed estimated median survival of 20 months and a primary patency rate \pm SE at $6,12,18$ and 24 months of $91.3 \% \pm$ $0.04 \%, 80.7 \% \pm 0.07 \%, 53.8 \% \pm 0.10 \%$ and $34.2 \pm 0.1 \%$, respectively. For fistula younger than six months, median survival was 17.67 months and primary patency rate \pm SE at 6 months, 12 months, 18 months and 24 months was $91.7 \pm 0.08 \%, 57.1 \pm 0.14 \%, 23 \pm 0.14 \%, 11.4 \% \pm 0.1 \%$, respectively. Logrank test showed a statistically significant difference between the survival rates, $\mathrm{P}=0.04$ (Fig. 3).

Cumulative mean patency from the time of fistula establishment to fistula loss, end of the study or reinterven-
TABLE II - TYPE AND LOCATION OF STENOSIS

\begin{tabular}{|c|c|}
\hline Stenosis & Fistulas $(n=71)$ \\
\hline \multicolumn{2}{|l|}{ Type of stenosis } \\
\hline Complete occlusion of venous outflow & $\begin{array}{c}9^{*} \text { (Seven fistulas }<6 \text { months } \\
\text { old, and two fistulas } \\
>6 \text { months old })\end{array}$ \\
\hline Single Stenosis & $42(59.2 \%)$ \\
\hline Multiple Stenosis & $29(40.8 \%)$ \\
\hline Treated Lesions by PTA & 56 \\
\hline Single Stenosis & 30 \\
\hline Multiple Stenosis & 26 \\
\hline FAV $<6$ months & 31 \\
\hline Complete occlusion DV not PTA & 6 \\
\hline Complete occlusion DV by PTA & 1 \\
\hline Single Stenosis treated by PTA & 12 \\
\hline Artery & 0 \\
\hline Anastomosis & 0 \\
\hline JAV & 4 \\
\hline DV & 8 \\
\hline Stenosis not treated by PTA & 7 \\
\hline Single stenosis & 3 \\
\hline Multiple stenosis** & 4 \\
\hline Multiple Stenosis treated by PTA & 5 \\
\hline Artery+JAV & 1 \\
\hline Artery + DV & 1 \\
\hline Anastomosis +JAV & 1 \\
\hline $\mathrm{JAV}+\mathrm{DV}$ & 1 \\
\hline Artery+AV+JAV & 1 \\
\hline FAV $>6$ months & 40 \\
\hline Complete occlusion DV not PTA & 2 \\
\hline Single Stenosis treated by PTA & 17 \\
\hline Artery & 1 \\
\hline $\mathrm{AV}$ & 1 \\
\hline JAV & 6 \\
\hline DV & 9 \\
\hline Multiple Stenosis treated by PTA & 21 \\
\hline Artery+AV & 1 \\
\hline Artery+JAV & 1 \\
\hline$A V+J A V$ & 5 \\
\hline $\mathrm{AV}+\mathrm{DV}$ & 4 \\
\hline$J A V+D V$ & 10 \\
\hline Multiple stenosis not PTA & 0 \\
\hline
\end{tabular}

Anatomic success of PTA

$100 \%(56 / 56)$

Clinical success of PTA

$98.2 \%(55 / 56)$

Location of stenosis

Single

Artery

Anastomosis

Juxta anastomosis

Venous outflow

42

2

3

10

27

Multiple

Artery+anastomosis

Artery+juxta

Artery+ anastomosis +juxta

Artery+ venous outflow

Anastomosis + juxta-anastomosis

Anastomosis+ venous outflow

Juxta+ venous outflow

29

3

2

1

2

6

4

11

$\mathrm{AV}$, anastomosis; DV, drainage vein; JAV, juxta-anastomosis; PTA, percutaneous angioplasty.

*One of these fistulas was successfully submitted to angioplasty, but suffered early thrombosis; **All associated with a very narrowed artery over its entire extension, with no visible stenosis; one patient also had an aneurysm) 

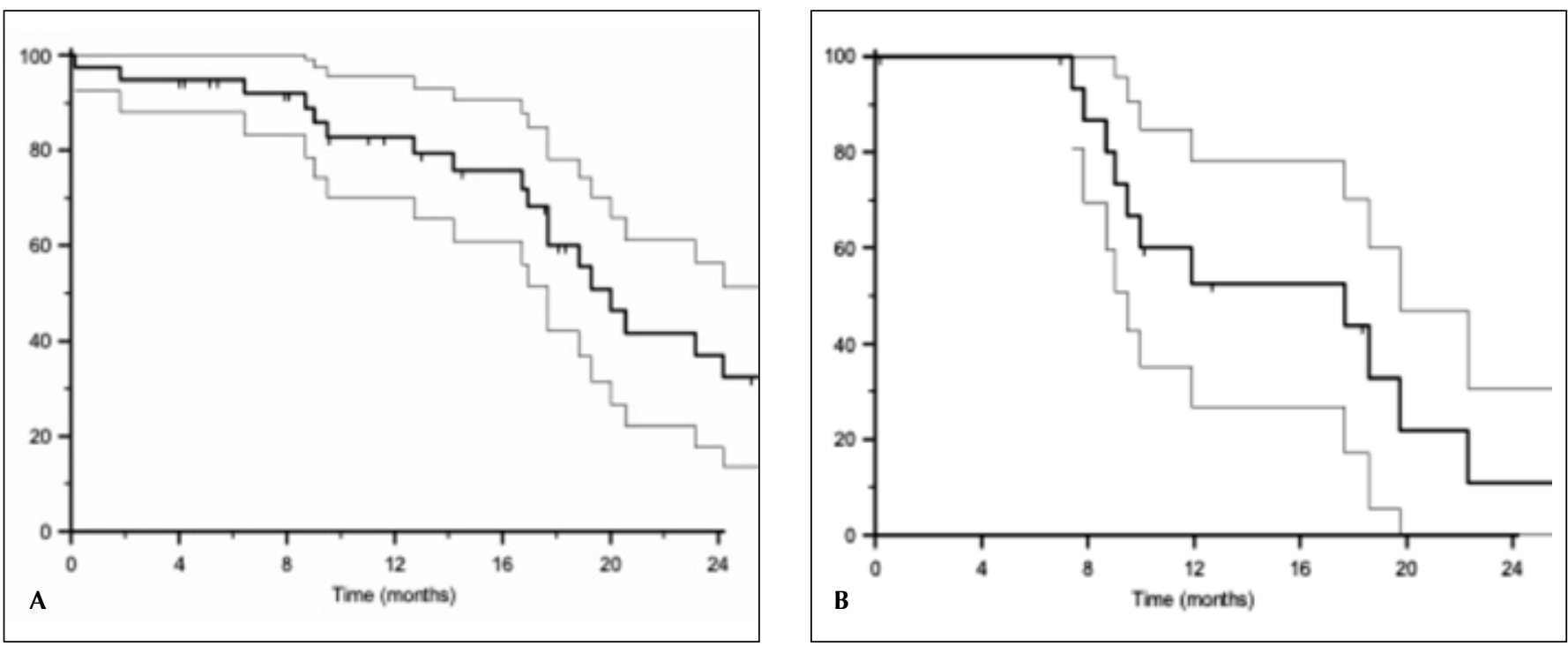

Fig. 3 - Kaplan Meier curve of estimated primary patency after first angioplasty in fistula older than 6 months (A) and $<6$ months (B). Crosses indicated censored observations and 95\% confidence intervals are represented by the less dark line.

TABLE III - SURVIVAL OF RADIOCEPHALIC AND BRACHIOCEPHALIC FISTULAS

\begin{tabular}{lccccc}
\hline & $\begin{array}{c}\text { Median } \\
\text { Survival }\end{array}$ & $\mathbf{6}$ & $\mathbf{1 2}$ & $\mathbf{1 8}$ & $\mathbf{2 4}$ \\
\hline $\begin{array}{l}\text { Radio- } \\
\text { cephalic }\end{array}$ & 17.67 & $90.7 \pm 6.3 \%$ & $65.5 \pm 10.6 \%$ & $41.7 \pm 11.7 \%$ & $22 \pm 9.6 \%$ \\
$\begin{array}{l}\text { Brachio- } \\
\text { cephalic }\end{array}$ & 24.2 & $94.4 \pm 5 \%$ & $81.5 \pm 9.8 \%$ & $62.9 \pm 14 \%$ & $41.9 \pm 15.3 \%$ \\
\hline
\end{tabular}

tion was 32.79 months, median 25.60 months, ranging from 5.3 to 186.26 . Cumulative mean patency for fistula older than six months was 42.5 months, median 31 ranging from eight months to 186 months, and fistulas less than six months old had a cumulative mean patency of 17 months, median 16.2 months, ranging from 5.3 months to 29.43 months, $\mathrm{P}<0.0005$.

Secondary patencies were determined on seven patients who underwent repeated angioplasty. Mean secondary patency was 11 months, median nine months. The Kaplan-Meier curve of estimated secondary patency showed an estimated survival of 19 months, with a secondary patency rate at nine months of $75 \pm 21.7 \%$.

Complications were five cases of acute rupture, which occurred during dilation $(8.9 \%)$, three treated by prolonged balloon insufflations. In two fistulas, a stent was required, and one of these fistulas was still patent at the end of the study. No other complications (fistula infection, development of aneurism, patient death or need for hospitalization) were observed. The mean procedure time was 35 minutes with median 41 minutes (28 to $218 \mathrm{~min}$ ).

Cox proportional hazard regression was performed for primary patency. The statistically significant factors were number of stenosis $(\mathrm{P}=0.005)$ and age of fistula (older or younger than six months at the time of intervention) $(\mathrm{P}=0.005)$.

\section{DISCUSSION}

Arterio-venous fistula (AVF) has the greatest longevity, lower complication rate (2) and the lowest upkeep value of all types of access (15). PTA is considered the preferred method of treatment for dysfunctional AVF since it appears to be as efficient as the surgical approach in terms of access survival and cost, even if primary patency for pre-emptive surgical repair is better $(89 \% \pm 6$, at 12 months) (16-19) . Surgery resolves AVF dysfunction by creating a new, more proximal anastomosis with subsequent venous capital loss, or by using graft interposition. It is noteworthy to point out that both surgical repair or endovascular treatment have better results if performed in nonthrombosed vessels (9).

Monitoring vascular blood flow plays an important role for early detection of stenoses and, consequently, reducing the rate of thrombosis $(20,21)$. If this surveillance is not performed correctly, angioplasty might lose its advantage over the surgical approach (22-24). We did not perform any access Qa monitoring at the time, before or after angioplasty, and the referral method for this study was based solely on clinical criteria; even so we achieved reasonable results, emphasizing the importance of clinical monitoring of hemodialysis accesses. Other surveillance techniques are associated with earlier detection of stenotic lesions, particularly when dysfunction comes from inflow lesions; however physical examination remains an invaluable monitoring method (25). 
EBPG recommend that only a functionally significant stenosis, defined as a decrease of more than $50 \%$ of normal vessel diameter, together with a reduction in access flow or in measured dialysis dose, or stenosis associated with difficulties in cannulation, painful arm, edema, hand ischemia or prolonged bleeding, should be assessed (3). In this study, all the stenoses presented a decrease of more than $75 \%$ of normal vessel diameter and were associated with clinical signs of dysfunction (e.g. weak or absent thrill).

Our study was performed on dysfunctional fistula and in whom angiography demonstrated an inflow stenosis. Venous problems have been regarded as the principal culprits for access dysfunction for a long time, with much less importance given to inflow problems which had an incidence of $0 \%$ to $4 \%$ (12). Although, in the last few years, inflow stenoses have been shown to be present in approximately $25 \%$ to $50 \%$ of the dysfunctional access (12-26). Both radiocephalic and brachiocephalic fistulas commonly fail because of lesions located within the perianastomotic region; however, more proximal stenoses can also occur in both cases, especially in the case of brachiocephalic fistulas (cephalic arch stenosis) (27). The histology of this venous stenosis is characterized by an aggressive neointimal hyperplasia in both AV grafts and fistulas whose mechanism is not completely understood but characterized by the presence of myofibroblasts, smooth muscle cells and microvessels in the neointima $(28,29)$.

Our data shows the role of percutaneous angioplasty in the treatment of inflow stenosis causing maturation failure or dysfunction of matured fistula. The estimated survival and patency rate as determined by Kaplan-Meier analysis are comparable to the data of others $(8,9,16,30)$ as shown by an estimated survival of $93.9 \% \pm 3.44 \%, 77.2 \pm 6.4 \%$, $52.4 \% \pm 8.5 \%$ respectively for 6,12 and 18 months. Interestingly, we found no difference between primary patency for radiocephalic fistulas and brachiocephalic fistulas, as opposed to others who have shown higher primary patency for radiocephalic fistulas $(8,9)$. In fact, in this study, primary patency rates for brachiocephalic fistulas are slightly superior to those found in the literature, that is $94.4 \%$, $81.5 \%, 62.9 \%$, respectively for 6,12 and 18 months versus $75 \%, 51 \%$ and $41 \%$ for 6,12 and 18 months (19), $51 \%$ and $39 \%$ (8) and $84 \%, 35 \%$ (9) for 6 and 12 months, respectively. Of note, other studies have included dysfunctional fistulas because of stenosis located at several sites, namely cephalic vein in the venous outflow, cephalic arch, subclavian or other central veins which acted as confounding factors, and most certainly account for this difference $(8,9)$. Rajan et al demonstrated that angioplasty of cephalic arch stenosis, predominantly, associated with brachiocephalic fistula, showed a primary patency rates at 3, 6 and 12 months of $76 \%, 42 \%$ and $23 \%$, respectively (31), in contrast to other studies that have included brachiocephalic fistula with stenosis located at different sites along the drainage vein $(9,19)$. In fact, percutaneous angioplasty has demonstrated disappointing data on the management of cephalic arch stenosis, probably because of multiple factors including the resistant nature of the stenosis, the development of early restenosis, as well as poor patency and high vein rupture rates (27).

The estimated secondary patency is rather good and comparable to others $(8,19)$. It is not possible to draw any definitive conclusions as statistical analysis was only performed in seven cases.

Our data also revealed that PTA is successful for old and young fistula, but the results are significantly better for older fistulae and for fistulae with only one stenosis. In some studies the age of the access at the time of intervention is not obvious, but Manninen et al clearly demonstrated that endovascular treatment is more effective for matured than for nonmatured fistula (32). Several publications have emphasized the value of endovascular techniques in the salvage of nonmaturing fistulas $(7,33,34)$.

Vascular stenosis is because of neointimal hyperplasia and the events leading to the development of this lesion appear to begin early on with surgical manipulation at the time of access construction, hemodynamic stress at the anastomotic site, venous puncture and uremia $(28,29)$. In this study $40.8 \%$ fistulae had multiple stenoses particularly located at the anastomotic and puncture area, similar to other data (7-9). Of note, our results showed a higher incidence of multiple lesions, although not statistically significant, on fistulae older than six months, particularly involving the puncture area and this finding is certainly related to venous punction (29).

Cox analysis showed that the age of fistula at the time of intervention and number of stenoses predicted patency. Patient age, side and location of the fistula and patient sex did not affect the results. We have no available data on diabetes.

We have used retrograde puncture as others $(8,35)$ although arterial puncture may provide a better characterization of the vascular tree, as the vascular stenosis may be located far from fistula anastomosis, such as the aortic arch (12). We were able to dilate arterial stenosis presented in 14.1\% (10/16 fistula) of fistulas. In six cases, we decided not to perform any angioplasty as the arteries presented a reduced caliber over their entire extension up to the elbow without visible stenosis and consequently, we assumed that the artery was anatomically inadequate to support the development of fistula. Recently, TurmelRodrigues et al argued that the arteries that did not enlarge after construction of an arteriovenous anastomosis, should be considered as an overall stenosed artery that could be mechanically dilated safely and effectively by an angioplasty balloon (36).

This study has the limitations inherent of being a retrospective and nonrandomized study. However, all the procedures were performed by two experienced physicians 
(two authors) and, therefore, variation in methods of treatment are avoided.

In conclusion, PTA appears to be an effective treatment for dysfunctional fistulas because of inflow stenosis particularly for matured fistulas, and able to treat the multiple lesions frequently presented. Multiple stenosis and younger age of fistulas were the factors that reduced patency rate after PTA.

Financial support: None.

Conflict of interest: None.
Address for Correspondence

Fernando Correia Caeiro Pereira

Serviço de Nefrologia

Rua da Beneficência n. ${ }^{\circ} 8$

1069-166 Lisboa

Portugal

fccaeiro@gmail.com

\section{REFERENCES}

1. Rayner HC, Pisoni RL, Bommer J, et al. Mortality and hospitalization in haemodialysis patients in five European countries: results from the Dialysis Outcomes and Practice Patterns Study (DOPPS). Nephrol Dial Transplant. 2004;19(1):108-120.

2. Pisoni RL, Arrington CJ, Albert JM, et al. Facility hemodialysis vascular access use and mortality in countries participating in DOPPS: an instrumental variable analysis. Am J Kidney Dis. 2009;53(3):475-491.

3. Tordoir J, Canaud B, Haage P, et al. EBPG on Vascular Access. Nephrol Dial Transplant. 2007; 22 Suppl 2: ii88117.

4. Rodrigues JA, Armadans L, Ferrer E, et al. The function of permanent vascular access. Nephrol Dial Transplant. 2000;15(3):402-408.

5. Maya I, O'Neal J, Young C, Barker-Finkel J, Allon M. Outcomes of brachiocephalic fistulas, transposed brachiobasilic fistulas, and upper arm grafts. Clin J Am Soc Nephrol. 2009;4(1):86-92.

6. Miller PE, Tolwani A, Luscy CP, et al. Predictors of adequacy of arteriovenous fistulas in hemodialysis patients. Kidney Int. 1999;56(1):275-280.

7. Clark TW, Cohen RA, Kwak A, et al. Salvage of nonmaturing native fistulas by using angioplasty. Radiology. 2007;242(1):286-292.

8. Rajan DK, Bunston S, Misra S, Pinto R, Lok CE. Dysfunctional autogenous hemodialysis fistulas: outcomes after angioplasty--are there clinical predictors of patency? Radiology. 2004; 232(2):508-515.

9. Turmel-Rodrigues L, Pengloan J, Baudin S, et al. Treatment of stenosis and thrombosis in haemodialysis fistulas and grafts by interventional radiology. Nephrol Dial Transplant. 2000;15(12):2029-2036.

10. Dixon BS. Why don't fistulas mature? Kidney Int. 2006;70(8):1413-1422.
11. Falk A. Optimizing hemodialysis arteriovenous fistula maturation. J Vasc Access. 2011;12(1):1-3.

12. Asif A, Gadalean F, Merrill D, et al. Inflow stenosis in arteriovenous fistulas and grafts: a multicenter, prospective study. Kidney Int. 2005;67(5): 1986-1992.

13. Gray RJ, Sacks D, Martin LG, Trerotola SO. Reporting standards for percutaneous interventions in dialysis access. Technology Assessment Committee. J Vasc Interv Radiol. 1999;10(10):1405-1415.

14. Aruny JE, Lewis CA, Cardella JF, et al. Quality improvement guidelines for percutaneous management of the thrombosed or dysfunctional dialysis access. Standards of Practice Committee of the Society of Cardiovascular \& Interventional Radiology. J Vasc Interv Radiol 1999;10(4):491-498.

15. USRDS 2010 Annual Data Report: Atlas of Chronic Kidney Disease and End-Stage Renal Disease in the United States, National Institutes of Health, National Institute of Diabetes and Digestive and Kideney Diseases, Bethesda, MD, 2010. Costs of end-stage renal eisease. www.usrds.org/2010/view/ v2_11.asp\#e.

16. Tessitore N, Mansueto G, Lipari G, et al. Endovascular versus surgical preemptive repair of forearm arteriovenous fistula juxta-anastomotic stenosis: analysis of data collected prospectively from 1999 to 2004. Clin J Am Soc Nephrol. 2006; 1(3):448-454.

17. Lipari G, Tessitore N, Poli A, e tal. Outcomes of surgical revision of stenosed and thrombosed forearm arteriovenous fistulae for haemodialysis. Nephrol Dial Transplant. 2007;22(9):2605-2612.

18. Napoli M, Prudenzano R, Russo F, et al. Juxta-anastomotic stenosis of native arteriovenous fistulas: surgical treatment versus percutaneous transluminal angioplasty. J Vasc Access. 2010;11(4):346-351.

19. Asif A, Lenz O, Merril D, et al. Percutaneous management of perianastomotic stenosis in arteriovenous fistulae: results of a prospective study. Kidney Int. 2006;69(10):1904-1909.

20. Besarab A, Asif A, Roy-Chaudhury P, Spergel LM, Ravani P. 
The native arteriovenous fistula in 2007. Surveillance and monitoring. J Nephrol. 2007; 20(6):656-667.

21. Tessitore N, Lipari G, Poli A, et al. Can blood flow surveillance and preemptive repair of subclinical stenosis prolong the useful life of arteriovenous fistulae? A randomized controlled study. Nephrol Dial Transplant. 2004;19(9): 2325-2333.

22. Mccarley P, Wingard RL, Shyr Y, Pettus W, Hakim RM, Ikizler TA. Vascular access blood flow monitoring reduces access morbidity and costs. Kidney Int. 2001;60(3):1164-1172.

23. Wijnen $E$, Planken $N$, Keuter $X$, et al. Impact of a quality improvement programme based on vascular access flow monitoring on costs, access occlusion and access failure. Nephrol Dial Transplant. 2006;21(12):3514-3519.

24. Schwab SJ, Oliver MJ, Suhocki P, McCann R. Hemodialysis arteriovenous access: detection of stenosis and response to treatment by vascular access blood flow. Kidney Int. 2001;59(1):358-362.

25. Tessitore N, Bedogna V, Lipari G, et al. Bedside screening for fistula stenosis should be tailored to the site of the arteriovenous anastomosis. Clin J Am Soc Nephrol. 2011;6(5):1073-1080.

26. Badero OJ, Salifu MO, Wasse H, Work J. Frequency of swing-segment stenosis in referred dialysis patients with angiographically documented lesions. Am J Kidney Dis. 2008;51(1):93-98.

27. Kian K, Asif A. Cephalic arch stenosis. Semin Dial. 2008;21(1):78-82.

28. Lee $T$, Roy-Chaudhury P. Advances and new frontiers in the pathophysiology of venous neointimal hyperplasia and dialysis access stenosis. Adv Chronic Kidney Dis. 2009;16(5):329-338.
29. Roy-Chaudhury P, Sukhatme VP, Cheung AK. Hemodialysis vascular access dysfunction: a cellular and molecular viewpoint. J Am Soc Nephrol. 2006;17(4):1112-1127.

30. Beathard GA, Arnold P, Jackson J, Litchfield T. Aggressive treatment of early fistula failure. Kidney Int. 2003;64(4):14871494.

31. Rajan DK, Clark TW, Patel NK, Stavropoulos SW, Simons ME. Prevalence and treatment of cephalic arch stenosis in dysfunctional autogenous hemodialysis fistulas. J Vasc Interv Radiol. 2003;14(5):567-573.

32. Manninen H, Kaukanen E, Mäkinen K, Karhapää P. Endovascular salvage of nonmaturing autogenous hemodialysis fistulas: comparison with endovascular therapy of failing mature fistulas. J Vasc Interv Radiol. 2008; 19(6):870-876.

33. Raynaud A, Novelli L, Bourquelot P, Stolba J, Beyssen B, Franco G. Low-flow maturation failure of distal accesses: Treatment by angioplasty of forearm arteries. J Vasc Surg. 2009;49(4):995-999.

34. Nassar GM, Nguyen B, Rhee E, Achkar K. Endovascular treatment of the "failing to mature" arteriovenous fistula. Clin J Am Soc Nephrol. 2006;1(2): 275-280.

35. Duijm LE, van der Rijt RH, Cuypers PW, et al. Outpatient treatment of arterial inflow stenoses of dysfunctional hemodialysis access fistulas by retrograde venous access puncture and catheterization. J Vasc Surg. 2008; 47(3):591598

36. Turmel-Rodrigues L, Boutin JM, Camiade C, Brillet G, Fodil-Chérif $M$, Mouton A. Percutaneous dilation of the radial artery in nonmaturing autogenous radial-cephalic fistulas for haemodialysis. Nephrol Dial Transplant. 2009; 24(12):3782-3788. 
Copyright of Journal of Vascular Access is the property of Wichtig Editore and its content may not be copied or emailed to multiple sites or posted to a listserv without the copyright holder's express written permission. However, users may print, download, or email articles for individual use. 